\title{
Manufacturing technology sourcing practices in the USA
}

\section{T.S. Baines, D.E. Whitney and C. Fine}

\section{Introduction}

Contrasts between the practices of US and Japanese manufacturers have been a rich source for research in recent years. An area that has been given particular attention is product sourcing and the associated relationship between manufacturing company and component supplier. However, a second set of sourcing decisions occurs in companies that has almost been completely ignored by the literature. This is the area of manufacturing technology sourcing, and is concerned with the origins of the equipment used within a factory to produce products. The absence of literature suggests that this important technology issue may well be neglected by researchers and industrialists alike.

This paper first describes research that has investigated manufacturing technology sourcing policies, and the way in which they were formed within a variety of US organizations. The fieldwork has revealed a number of interesting conclusions. Primarily, it has reinforced the view that US companies usually prefer to buy rather than make their production equipment. Indeed, some companies have divested from equipment manufacture as part of a process to regain business focus. In contrast, a small selection of companies is vertically integrated into the technology source. They believe that such an approach can make a difference to the performance of the resulting technology. Furthermore, even in the companies that prefer outsourcing policies, the competitive pressures may force them into greater involvement with equipment manufacture than they would like. This tends to occur in instances where there is a reliance on unique manufacturing capabilities for the competitiveness and differentiation of products. In these cases, integration into equipment manufacture may be the only sustainable policy in the long term.

To explain the policies of the companies in our sample, the processes of policy formation have been investigated. Various motives were given for the actions of companies, and these succinctly fit into five categories. On this basis, a decision to make or buy a manufacturing technology was seen to be based upon an attempt to either:

- retain business focus; •

- acquire a manufacturing technology efficiently; •

- acquire better manufacturing technology capabilities; •

- better support a manufacturing technology in service; or •

- defend a unique manufacturing capability.

In most cases, policies appear to have evolved within organizations, rather than being based on some explicit decision-making process. We feel that this situation is unsatisfactory, and that practising managers should form such decisions in a more structured manner, and should be provided with the aids to do so. Therefore, the second part of this paper goes some way to overcoming this deficiency by proposing a methodology to help in the formation of a manufacturing technology sourcing decision. This methodology is a decision framework that provides a guide to ensure proper consideration of important factors concerned with vertical integration into the manufacturing technology supply base.

The structure of this paper is as follows. The next section provides some background to the technology sourcing decision. Section 3 describes the study objectives and the research design, and section 4 summarizes the research findings. Section 5 builds on this foundation and presents the methodology that has been developed. Finally, work is then drawn to a conclusion in section 6. 


\section{Background}

This paper is concerned with the physical production process, and the sources from which such technology is acquired. This is associated with vertical integration, but this paper does not consider supplier relationship issues, e.g. single versus multiple sourcing.

There appears to be a contrast in the sourcing practices of some Japanese and US companies. Fine and Whitney (1996) have observed that Japanese manufacturing companies make a surprisingly large fraction of their equipment, while US companies purchase much of their equipment from other companies. Indeed, such an approach is advocated by noted Japanese production specialists, e.g. Shingo (1990) sees a significant benefit from company personnel being on hand to execute immediate repairs and improvements to technology. In contrast, a recent emphasis in US industry has been a focus on core competencies and a divestment in non-core activities. In many companies, technology manufacture appears to be seen to be one such non-core activity, and is accused of distracting time and resources from the core business. For example, Gi et al. (1990) is critical of top management teams that attempt to save a few dollars by '... doing it ourselves'. They therefore favour outsourcing, applauding Motorola for having a formal policy of 'do not create what already exists somewhere else'.

It appears that the literature is inconsistent as to the approach a company should take to technology sourcing. Some clarification is provided by Hayes and Wheelright (1984). They provide a four-stage classification of the role that a manufacturing function can have within a business. At stage 1, the manufacturing function is internally neutral, being reactive and restricting the success of the company, whereas at stage 4, manufacturing is progressive and the competitiveness of the company rests to a significant degree on manufacturing capabilities. Stage 4 companies are synonymous with the acclaimed status as World Class Manufacturers (WCM).

Hayes and Wheelright state that a characteristic of stage 1 companies is that they prefer safe technologies from vendors. In contrast, companies at stage 4 anticipate the potential of new manufacturing practices and technologies, and seek to acquire expertize in them long before their implications are apparent. On this basis, the importance of technology sourcing issues may be dependent on the role that manufacturing capabilities take within a business strategy. As more companies strive to become WCMs, it is therefore important that they become competent in deciding whether to make-or-buy their manufacturing technology. To provide a foundation for making such a decision, it is important to know more clearly what policies are currently practised and why they are adopted.

\section{The research process design}

Fine and Whitney (1996) recognize a contrast in US and Japanese practices, but they submit that their research is based on observation and speculation. They call for a rigorous study of the technology sourcing policies followed by American companies, along with an investigation into the manner by which such policies are formed. Therefore, the aim of this research has been to carry out a study that explores and describes manufacturing technology sourcing practices within organizations. In particular, the following questions have been addressed.

(1) What manufacturing technology sourcing policies do organizations actually practice?

(2) Are these sourcing policies conscious intentions?

(3) How are these sourcing policies formed?

(4) What factors feature in a rational process of forming a sourcing policy?

This section describes the research process that has been used to realize this aim.

\subsection{Overview of research method and scope}

The research aim requires an intimate understanding of how sourcing policies for technology acquisition are formed in manufacturing organizations. Unfortunately, there is a paucity of research literature in this field, yet personnel in companies are implicitly making a sourcing decision whenever a new production facility is acquired. The research method has therefore been based around a series of short industrial case studies that describe recent technology acquisition projects at a variety of manufacturing plants. 
The case study research was conducted by following a precise methodology given by Yin (1994). In accordance with Yin, the first stage of the research was to form a proposition about the types of manufacturing sourcing policies that may exist and the decision processes through which they could be formed. This is explained in sections 3.2 and 3.3. Using this proposition as a basis, an initial series of constructs was identified around which to base the case study. The case study constructs were then expanded to include the continuous interplay among the ideas of context, as well as the content and process of change (Pettigrew 1988, Whipp et al. 1991). The resulting procedure for conducting the field research is shown in figure 1.

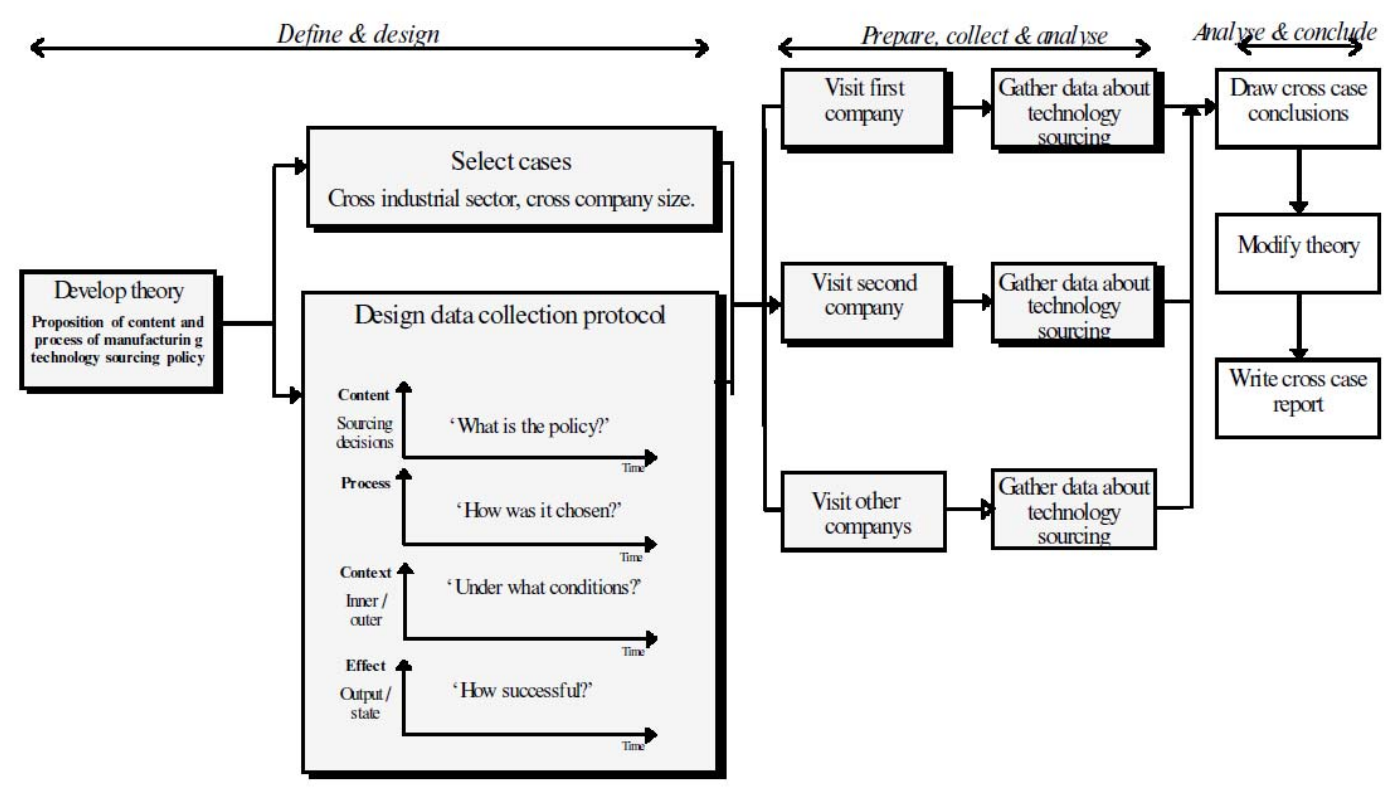

Figure 1. The case study research methodology based on Yin (1994).

An attempt was also made to describe the success of policies in each case study. However, many factors dynamically integrate to determine the performance of a manufacturing system and it is di cult to isolate the effect of one in particular. Harrison (1994) suggests that the effect of an action can be measured in two ways: changes in output goals for a system and/or changes in internal system state. As the practical manifestation of a technology sourcing policy will be the acquisition of a production facility, an assumption was made that the performance of a technology reflects the sourcing policy, and in turn the competence of the process used to form the policy. The performance of such a technology can then be considered in the manner suggested by Harrison. Figure 2 illustrates how technology performance can be measured using this method.

\begin{tabular}{|c|c|c|}
\hline Type & Criteria & $\begin{array}{l}\text { Proposed measures for }{ }_{1} \\
\text { evaluation of technology }\end{array}$ \\
\hline Output goals & $\begin{array}{l}\text { Goal attainment } \\
\text { Qunitity outputs and quality } \\
\text { outputs }\end{array}$ & $\begin{array}{l}\text { Perceivod suocessffailure of } \\
\text { technology. } \\
\text { Perceivod improvements in } \\
\text { - Production volume flexibility } \\
\text { - Lead-time } \\
\text { - Delivery perfornance } \\
\text { - Features of product design } \\
\text { - Rejoctsretums/complaints } \\
\text { - Design flexibility } \\
\text { - Producteost }\end{array}$ \\
\hline \multirow{3}{*}{$\begin{array}{l}\text { Intemal } \\
\text { system state }\end{array}$} & $\begin{array}{l}\text { Cost (other) of production ar } \\
\text { service }\end{array}$ & $\begin{array}{l}\text { Pfficiency in terms of wastage/ } \\
\text { downtime. }\end{array}$ \\
\hline & $\begin{array}{l}\text { Human outcomes induling } \\
\text { consensurdconflict }\end{array}$ & $\begin{array}{l}\text { Employee satisfaction with } \\
\text { technology, including } \\
\text { absentereism, heal th and safety, } \\
\text { strikes, stoppages, disputes. }\end{array}$ \\
\hline & Fit & $\begin{array}{l}\text { Conpatibility with other policies } \\
\text { and strategies, including, material } \\
\text { and information systems } \\
\text { dependant and service activities } \\
\text { manaagement structure. }\end{array}$ \\
\hline
\end{tabular}

\footnotetext{
${ }^{1}$ These operational measures have been chosen to evaluate the effectiveness of a chosen manufacturing technology. The premise is that the performance of a technology reflects the sourcing policy, and hence the competence of the process used to form the policy. A limitation is that this assumes that a policy is precisely followed and that perfect technology implementation is achieved.
} 
The detailed nature of the content, process and context data meant that semi-structured interviews were chosen as the mechanism to collect the data necessary to construct the case studies. A questionnaire was formed, and this was used as a guide for the interviewer. To expose the data required from plants, a cross-section of management was identified to be interviewed, this ranged from executive o cers to shop-- oor personnel. The interviews commenced by identifying three recent technology acquisitions within the plant, and using these to initially stimulate the ensuing discussions.

On completion, the questionnaires and interview notes were combined to form the case study-style description of prevailing content, context and process associated with technology sourcing at each plant. A cross-case comparison could then be conducted to provide the results discussed in section 4 .

Finally, the case study approach is relatively resource intensive. Therefore, this study has focused on a group of 14 manufacturing plants and concentrated on manufacturing hardware, e.g. machining centres, robotics and automation. These plants have been taken from a variety of industry sectors, including small electromechanical products, small plastic assemblies, automotive and motorcycle manufacture. Each plant is an autonomous business unit, though some do belong to common business corporations.

\subsection{Anticipated manufacturing technology sourcing policies}

Yin (1994) advocates that the researcher should have a proposition of the form of the phenomena under study to act as a guide to data collection. Therefore, it is necessary to speculate the types of manufacturing technology sourcing policies that may exist along with the methods through which they may be formed.

Policy may be defined as a course of actions, a strategy, principle or rule. The strategic management literature tends to consider policy as being associated with relatively autonomous decisions within an organization, whereas strategy dynamically co-ordinates and integrates functional area policies over time (Hofer and Schendel 1978). It is therefore appropriate to use the term policy when focusing on manufacturing technology sourcing issues as an individual set of decisions within an organization.

A policy may exist within an organization without it being explicitly declared. Again from the strategy literature, Mintzberg (1987) argues that intended strategy refers to a formal intention, whereas an emergent strategy can be observed when a non-intentional pattern can be recognized in past actions. Similarly, a strategy that has been realized in practice may well have both intended and emergent components. As strategy deals with the coordination of policies, this association means that the intended and emergent distinction can also be applied to a policy.

The term policy content can be used to describe the actual decision made. Therefore, the content of a company's sourcing policy is the chosen extent of involvement with a supplier, e.g. a decision to source a specific manufacturing technology from outside the host organization. Fine and Whitney (1996) offer one insight to the various types of policy content that may be expected, and these can be grouped into the following stages:

- specification of technology;

- general design of technology;

- detailed design of technology;

- construction of technology.

On this basis, a company's sourcing policy describes the extent of involvement with technology suppliers. This policy may be explicit within an organization, in which case it can be referred to as intended. Alternatively, a policy may appear as an inadvertent trend when past actions are analysed, in which case it can be referred to as emergent. 


\subsection{Anticipated decision processes for forming a manufacturing technology sourcing policy}

The decision process refers to the mechanism through which policies are formed in an organizational setting. The term decision process is often only associated with a formalized decision-making activity. If such explicit processes exist in an organization they are likely to be documented and self-evident.

Less obvious forms of decision-making may exist. For example, Mintzberg (1976) investigates unstructured processes where a rational process is apparent in hindsight. Such a situation may exist when personnel in a company are forming a sourcing policy in the action of acquiring a new production facility. On the basis of empirical work, Mintzberg (1976) has developed a flow diagram that illustrates in detail the activities that may occur in an unstructured decision-making process.

Using this flow diagram as a guide, the data collection protocol has been designed to explore the activities that may occur if a policy is formed by an unstructured decision process. A decision may be formed by other methods that seem to be less rational, e.g. where a decision is made through emotion, tradition, beliefs, etc. Similarly, a decision process may appear to be absent or external to the particular situation being studied. Such a situation occurs when operational managers in an organization are presented with a policy that has been formed by an interventionist chief executive officer. On this basis, at least three decision processes may occur to form a technology sourcing policy in an organization. These are:

- formalized: explicit and documented decision-making process;

- unstructured: rationale for making decisions apparent in hindsight;

- evolutionary: process apparently absent.

Decision formed by emotion, tradition, beliefs, or decision given from outside. Formation of an intended policy may incorporate all three approaches, but an emergent policy cannot have been formally conceived.

\section{Industrial findings}

The research method has been applied at 14 manufacturing plants. To enable this industrial research, and to ensure future cooperation with researchers, the identity of the companies involved has been protected. Therefore, no reference will be made to companies individually. Rather, they will be referred to as plants $1 \pm 14$. A short profile of each plant is given in table 1 . This section provides a summary of the findings of this research work.

- Finding 1: There is indeed a preference amongst theUS organizations studied not to become involved with equipment manufacture.

The preferred practice is involvement with technology specification, but then to outsource design and manufacture. Most of the companies in our sample have some independence from suppliers for knowledge about the design of a technology, but are totally dependent on outside resources for technology construction. The extent of vertical integration varies across technologies within a plant. Where complete vertical integration did occur, it was only for very specific technologies.

- Finding 2: Intended sourcing policies do exist where manufacturing capabilities are instrumental in differentiating a product in the market, emergent policies are apparent where the manufacturing capabilities have a limited influence on product competitiveness.

There does appear to be a direct relationship between the role of manufacturing capabilities in a business and the existence of an intended policy, though there is no corresponding relationship in our sample with policy content. This relationship can be illustrated graphically as shown in figure 3 . This figure shows how the awareness of a technology within an industry can change over time. For example, in the early 1970s, CNC technology was emerging and few applications existed, but today this technology is pervasive throughout the manufacturing industry. This figure also shows our view of the relationship between technology life cycle and the form of a technology sourcing policy. This conclusion differs from that of Hayes and Wheelwright (1984) (section 2). We believe that it is the explicitness rather that the content of the policy that changes as the role of manufacturing in a business increases in importance. A company that Hayes and Wheelwright 
would class as at stage 4 may have an explicit policy, but this is not necessarily a policy of complete technology manufacture.

Some companies intend to avoid integration and achieve this goal. However, others may aspire to this policy but are forced into technology development. This occurs where manufacturing capabilities are very important to the business, yet the sourcing policy conflicts with the development of manufacturing capabilities. In these cases, the achievable policy options appear to be either integration, or being able to exhibit exceptional control in a supplier relationship.

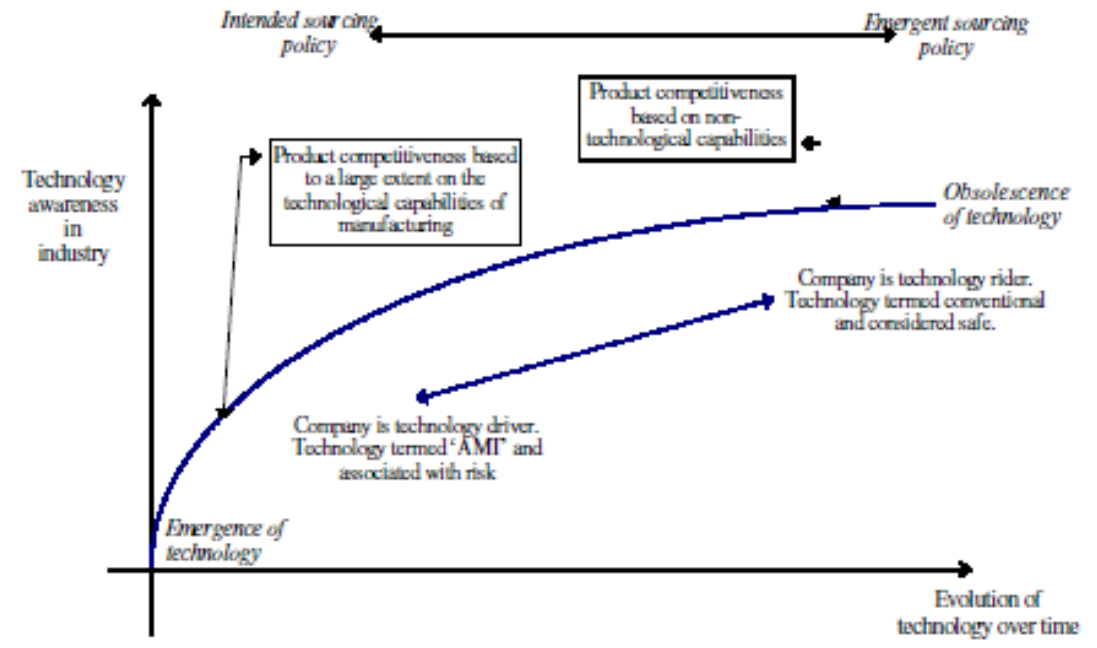

Figure 3. A relationship between manufacturing technology life cycle and sourcing policy.

- Finding 3: There was a complete absence in our sample of a formalized decision process for determining a manufacturing technology sourcing policy within an organization.

No plants at all could demonstrate a procedure for establishing the source of a manufacturing technology. In some cases, complementary procedures were in place, e.g. those for product sourcing and new technology introduction. This situation was particularly surprising with plants 6 and 7 , where intended policies were quite forcefully espoused and pervasive throughout these organizations. Four plants exhibited some form of unstructured process for forming a technology sourcing policy. Plant 14 demonstrated the most advanced and complete process. However, even in this case, the process was neither formalized nor documented. There were 10 cases where a policy existed, but the process by which this had been achieved was not apparent. Intriguingly, plants $5 \pm 7$ each had strong intended policies, but in each case these appeared to have evolved within the company.

- Finding 4: The companies studied choose a particular level of integration for one of the following reasons; retention of business focus; efficient acquisition of a manufacturing technology; acquisition of better manufacturing capabilities; support of a manufacturing technology; and defence of a unique manufacturing capability.

Personnel at each plant were asked to give reasons for the sourcing policy that they practised. Through analysing the responses to this question, five drivers have been identified that represent the arguments given by companies for greater or lesser extents of vertical integration. These drivers are not related to set policies, rather they explain alternate levels of integration that companies adopt to suit their circumstances. Each category represents a perspective for viewing the drivers or motives behind a sourcing decision, and each of these deserves a fuller description, which is given as follows.

\subsection{Retention of business focus}

This category is concerned with focusing and developing the core activities of a business, and avoiding distraction into other activities.

Avoiding unnecessary integration may ensure the availability of time and resources for the development of the company's core business. This situation is captured, though somewhat idiosyncratically, by the quotation 'our business is cars, not robots' (Fine and Whitney 1996). 
However, when presented with the quotation given above, sta at plant 6 retorted 'machine manufacturers only make machines, we make [our product]'. The implication is that external suppliers are focused at the design and manufacture of a technology, rather than appreciating the subtleties of producing the host company's product. This is a good example where a motive of attempting to improve business focus may indeed drive a company into greater or lesser extents of vertical integration.

\subsection{Acquire a manufacturing technology more efficiently}

A better built manufacturing technology can be measured in terms of: cost of the technology; time taken to acquire the technology or technologies in sufficient volume; and/or quality conformance of the technology to a specification.

The benefits of outsourcing are that the focus of a supplier on the production of a particular technology may favour cost, etc. Specialized knowledge and resources may be available, and there may be a benefit through scales of volume. Similarly, a supplier may be able to gain access to knowledge in industry, other industries, or competing manufacturing companies. This may mean that the time to acquire a technology can be significantly shorter than if a company attempted in-house development.

In contrast, outsourcing may mean the acquisition of a standard machine, having a series of capabilities that actually exceed those required by a company. Such capabilities will be reflected in higher technology cost. In-house manufacture may provide an adequate technology at a lower cost. Similarly, a company may be able to capitalize on its own manufacturing experience and facilities to reduce technology cost. This was apparent with plant 3 , where the company produced pneumatic test equipment and was well placed to provide its own testing facility. This also meant that if the company should need to purchase equipment, the employees were well experienced to do so. Likewise, the quality of the technology may benefit from in-house manufacture, as there is likely to be a closer association between technology builder and user.

\subsection{Acquire better manufacturing technology capabilities}

This is concerned with the production capabilities of the manufacturing technology, and can be defined in terms of production rate, reliability, accuracy, etc.

A company may choose to seek an external supplier, as did plant 7 where a novel forging method was sought to improve the strength characteristics of a crankshaft. The company had limited expertize in this technology, and therefore external suppliers were used to enable this production technology to be introduced into the company.

The benefits to a company of involvement with technology construction include first-hand knowledge of the product and the associated production task. This favours tailor-development of a technology to suit products. Subsequently, there is likely to be a greater awareness of the technological capabilities and this can aid product development.

A company is also likely to consider a project goal in terms of integration within its manufacturing system, this may differ from the goals of an external supplier. For example, staff at plant 8 criticised the understanding that suppliers have of a host company's manufacturing system.

\subsection{Better support a manufacturing technology}

This is concerned with ensuring the productive operation and continuous improvement of a technology in use.

A benefit of external technology suppliers is that they may have expertize, gained within other companies, to quickly trace a fault and repair a technology. Furthermore, this responsibility may be legally enforced through a service agreement. Such a warranty may help to counteract the cost and disruption of a breakdown. If a company is a large customer, e.g. plant 7, a supplier company may actually agree to permanently retain personnel at the company's site to deal with breakdown situations.

Benefits to a company of building a technology, are that knowledge and resources may be immediately available and within the control of the company if a breakdown occurs. This avoids issues about having to have sufficient leverage 
with suppliers, and similarly, logistics problems. This also favours continuous development of the technology, and provides a knowledge base that can also be used to improve technologies at the company's product suppliers.

\subsection{Defend a unique manufacturing capability}

A technology may be somehow uniquely important to the competitive edge of a company's products.

A manufacturing capability may be such that it enables product differentiation in a market, defending this differentiation was a principal concern in some plants. In such a case, a company may attempt to prevent a competitor from gaining access to a technology. The technology source may have a number of consequences if the defence of a technology is important.

It is possible, though unlikely, that a company will outsource equipment manufacture to defend a technology. Technologies can be defended in this way by business agreements or legally binding patents. In-house construction of a technology means that knowledge can be retained within the host company. In this way, a company may avoid the risk of sharing its competitive advantages with other customers of its suppliers.

\section{A methodology for forming a technology sourcing policy}

It is wrong to advocate a technology sourcing policy without appreciating the context of a company. There are right times to make and right times to buy (Higgins 1955).More recently, Bruck (1995) argues about product sourcing that no amount of observation of prevailing practice in different industries will reveal whether high or low vertical integration creates a competitive advantage. Every company must find its own optimum level of integration, and as our own work has shown, this may differ for technologies across an organization. Bruck goes on to say that a manufacturer must define the technical interface, this is the point at which a supplier's contribution fits into the manufacturer's own products.

There is very little published literature on technology sourcing and few guides exist to help the practising manager (Buchowicz 1991). Indeed, the whole arena of planning for technology tends to be an ad hoc and hit and miss affair (Swamidass 1987). A methodology is needed that provides a decision framework that is an aid to a company forming a technology sourcing decision. This section provides a brief overview of a decision process that we have formed for this purpose.

\subsection{Foundation of the methodology}

Manufacturing technology sourcing can be treated in a similar manner to product sourcing, i.e. to focus resources on core production technologies. Quinn (1995) argues that a company should concentrate its own resources on core competencies where it can achieve definable pre-eminence and provide unique value for customers. He sees that core competencies are the activities that offer a long-term competitive advantage, and thus must be rigidly controlled and protected. In this way, Porter (1985) suggests concentrating on technologies that have the greatest sustainable impact on cost or differentiation.

This, however, is a rather simplistic view of the technology sourcing decision, as the supplier base characteristics need to be taken into account. A company that has a weak supplier base may be forced into the design and construction of a technology not considered to be core. Alternatively, a company based in a supplier-rich location may develop strong supplier relationships that enable the outsourcing of core technologies.

The relationship between supplier base and company can be quantified to some extent in terms of the drivers identified in section 4 above. On the basis of these drivers, a company may choose to be involved to a greater or lesser extent in technology specification, design and construction.

In summary, two important principles are therefore apparent when considering technology sourcing. First, it is important to understand how a technology characterizes or influences the competitiveness of a product. Second, it is also important to take into account the capabilities of the company relative to technology supplier base. The 
factors in section 4 provide a mechanism for carrying out this comparison, and forming a technology sourcing decision. The following methodology has been formed on this basis.

\subsection{Overview of the process}

The methodology is outlined in figure 4 and seeks to forma sourcing decision for an individual technology. The methodology commences when the general form of the manufacturing technology required has been identified, but no final decision has been made on the source. An overview of the stages of the methodology are as follows.

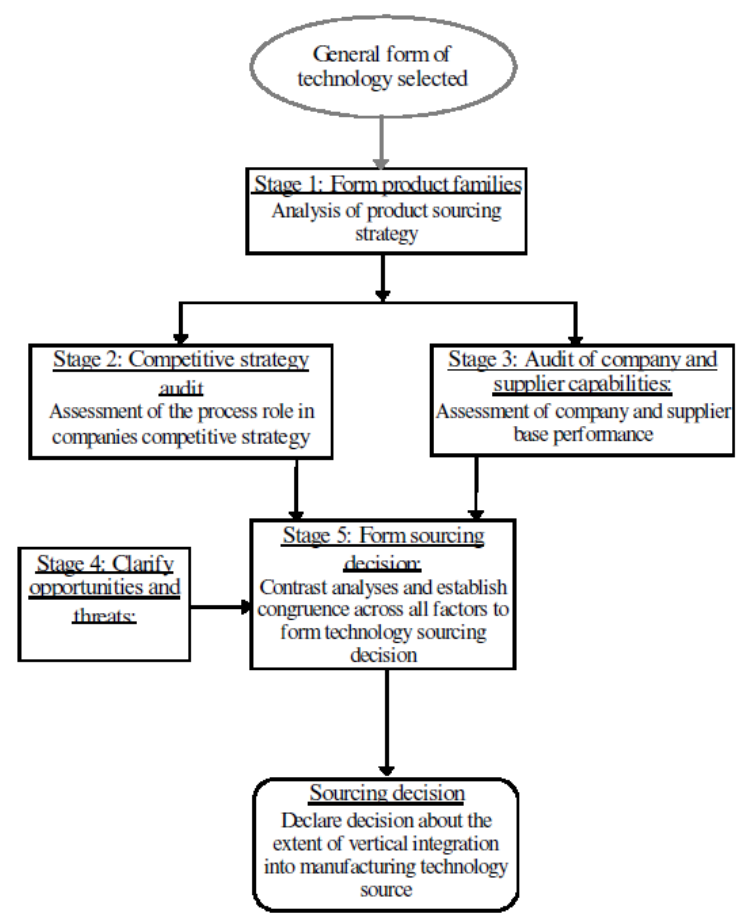

Figure 4. Outline of the methodology for deciding on the extent of vertical integration into technology source.

- Stage 1: Form product families

This stage is concerned with identifying or clarifying the product families with which a manufacturing technology is associated. This is necessary as a preliminary to appreciating how a technology contributes to the competitive strategy of a business. Product families can be formed by grouping together those products that compete in a similar way in a market.

Product family analysis and grouping should already exist in an organization. Company personnel should understand the concept of core products and how they relate to manufacturing. For example, core products define a company's business and their manufacture should be closely controlled, conversely non-core products are seen as commodities and are often externally sourced. Occasionally, the manufacture of noncore products may be retained in-house because a company's supplier base may not provide adequate service. The concept of core and non-core products helps to establish product families and provide some distinction on their relative importance to a technology. To aid the formation and ranking of product families, a worksheet has been developed. This worksheet is shown for two typical product families in figure 5 .

\begin{tabular}{|c|c|c|c|c|}
\hline Product family & $\begin{array}{c}\text { Sales as } \% \text { of } \\
\text { totalsales }\end{array}$ & $\begin{array}{c}\text { Contribution as } \% \\
\text { of total contribution }\end{array}$ & Market share & $\begin{array}{c}\text { Market growth/ } \\
\text { Stage of life cvcle }\end{array}$ \\
\hline $\begin{array}{c}500 \mathrm{cc} \text { Standard } \\
\text { utility petrol } \\
\text { engine. }\end{array}$ & $80 \%$ & $60 \%$ & $\begin{array}{c}40 \% \\
(2 \text { competitors each } \\
\text { with equal share) } \\
90 \%\end{array}$ & $\begin{array}{c}\text { Static / Mature } \\
\text { product }\end{array}$ \\
$\begin{array}{c}750 \text { oc High torque } \\
\text { at low speed, } \\
\text { utility engine. }\end{array}$ & $20 \%$ & $40 \%$ & (few competitors) & $\begin{array}{c}\text { High growth } / \text { new } \\
\text { product }\end{array}$ \\
\hline
\end{tabular}

Figure 5 . Worksheet to help in the definition of product families. 


\section{- Stage 2: Competitive strategy audit}

The competitive strategy audit provides a business perspective to the technology source decision. It clarifies how technological capabilities contribute to the immediate and ongoing competitiveness of product families. This is a three-step audit, and to aid the application of this audit a worksheet has been developed, and this is illustrated for a typical product family in figure 6 .

First to be considered is the efficiency with which a technology can be acquired, e.g. development time and cost. Second, consideration is given to how each product family competes in a market, and in turn the extent to which a technology is unique in supporting the competitiveness of a product family. The third step is a consideration of the need for ongoing support and development of a technology once operational.

\begin{tabular}{|c|c|c|c|}
\hline Technology acauisition factors & Essential & Desirahle & Comment \\
\hline Maximum allowable equipment cost & & $\$ 500,000$ & \multirow[t]{2}{*}{ - Based on current business plan } \\
\hline Required delivery schedule & $\begin{array}{l}\text { Installed by } \\
\text { February } 1997\end{array}$ & & \\
\hline Technology imnact factors & \begin{tabular}{|l|} 
Order qualifving \\
\end{tabular} & Order winning & Comment \\
\hline $\begin{array}{l}\text { 1. Product features } \\
\text { 2. Design flexibility } \\
\text { 3. Volume flexibility } \\
\text { 4. Lead tine } \\
\text { 5. Delivery performance } \\
\text { 6. Quality conformance } \\
\text { 7. Price(cost) }\end{array}$ & $\begin{array}{l}* \\
* \\
*\end{array}$ & $\begin{array}{l}* \\
*\end{array}$ & $\begin{array}{l}\text { - Cylinder head design essential to } \\
\text { engine performance } \\
\text { - Must respond to varying demands } \\
\text { - Delivery and quality essential }\end{array}$ \\
\hline $\begin{array}{l}\text { How unique is the technology in } \\
\text { providing the competitive characteristics } \\
\text { of the product family }\end{array}$ & High & $\frac{\operatorname{Law}}{*}$ & $\begin{array}{l}\text { - Technology not unique to industry } \\
\text { similar applications do exist. }\end{array}$ \\
\hline Technology development factors & High & Law & Comment \\
\hline Anticipated need for breakdown support & $*$ & & \multirow[t]{2}{*}{ - Complex equipment } \\
\hline Need for ongoing development & & $*$ & \\
\hline
\end{tabular}

Figure 6. An example of a completed worksheet for the competitive strategy audit.

\section{- Stage 3: Audit of company and supplier capabilities}

This analysis sets out to explore the possible sourcing options for a particular technology irrespective of products being produced. It proposes a wide range of factors that should be considered in a sourcing decision. These factors have again been grouped into three categories of technology acquisition, impact and development. These three categories and associated factors are featured in the completed worksheet shown in figure 7. The first category deals with the efficiency of technology acquisition, e.g. the cost and time taken to bring a manufacturing process into operation. The second category is concerned with technological impact. This deals with the manufacturing capabilities of a technology and how the exploitation of these can be controlled. The third category seeks to establish the most favourable technology source for gaining support. This last category of development is concerned with the maintenance and development of the host company's production processes. The sourcing option for each factor, in each of these categories, is intended to be considered individually. 


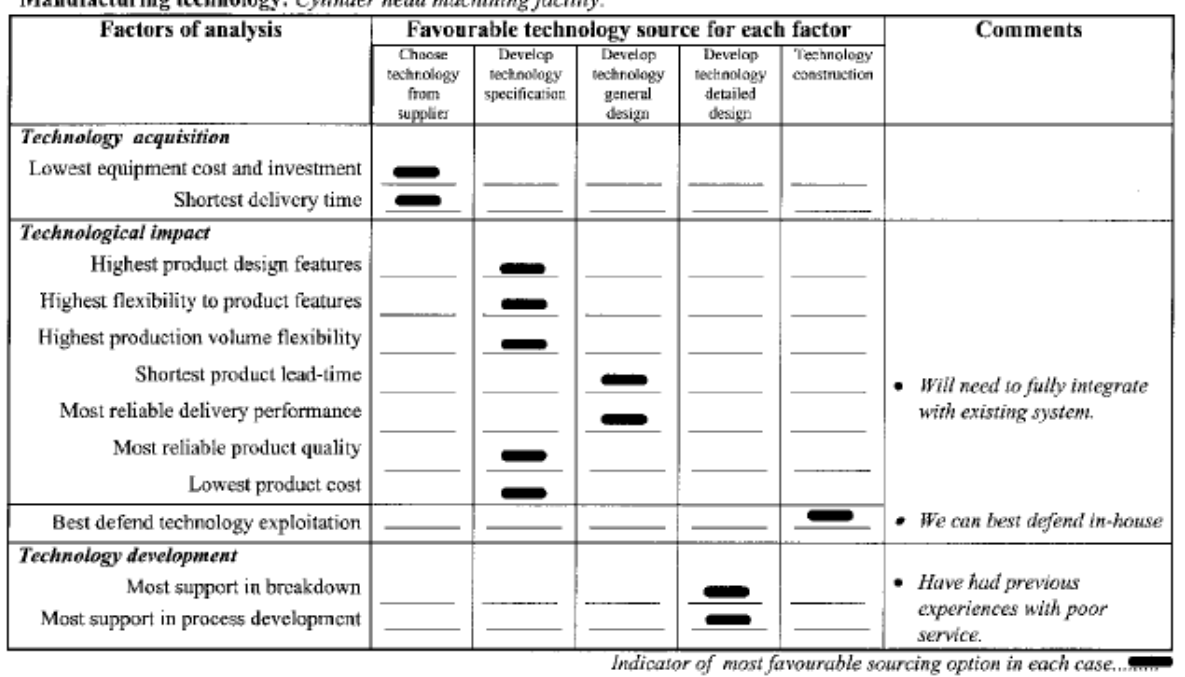

Note: The table is completed by prefixing each factor of analysis with the question 'what sourcing option will provide the..' The indicator is then placed at the intersection of the factor and the favoured sourcing option.

Figure 7. An example of a completed worksheet for the audit of company and supplier capabilities.

\section{- Stage 4: Clarification of opportunities and threats}

The technology choice decision should have considered such factors as product substitution and technology obsolescence issues. This stage therefore considers opportunities and threats as factors that may affect the technology sourcing decision. Threats may be future changes in the supplier circumstances that will affect a decision to outsource. Another threat may be that a company is in danger of being too reliant on one particular technology supplier. Opportunities may include building a supplier relationship that may aid future access to expertize. Opportunities and threats can be documented by stating the issue, its likely impact and probability of occurring. Once documented, these can then be referred to as the subsequent stages of the methodology are executed.

- Stage 5: Form sourcing decision

To forma sourcing decision for a particular technology, the preceding audit stages are combined. The company and supplier audit forms a foundation, and onto this the results of the competitive audit are introduced. This is illustrated in the worksheet shown in figure 8. The company and supplier audit should have identified the possible sourcing options for a technology, and the competitive analysis provides a profile of the business demands placed on a technology. By combining these analyses, the sourcing factors can first be distinguished as being of primary or secondary importance to the technology sourcing decision. A factor of primary importance is one where the competitive strategy audit has indicated that performance against the factor is essential. For instance, consider in the example given in figure 8 the factor of 'product lead-time'. This factor is essential to the market differentiation of the product being considered (an order qualifying criteria). Therefore, the sourcing activity that provides a technology that is most supportive of this factor is of primary importance. Conversely, 'defence of technology exploitation' is in this instance of secondary importance. 


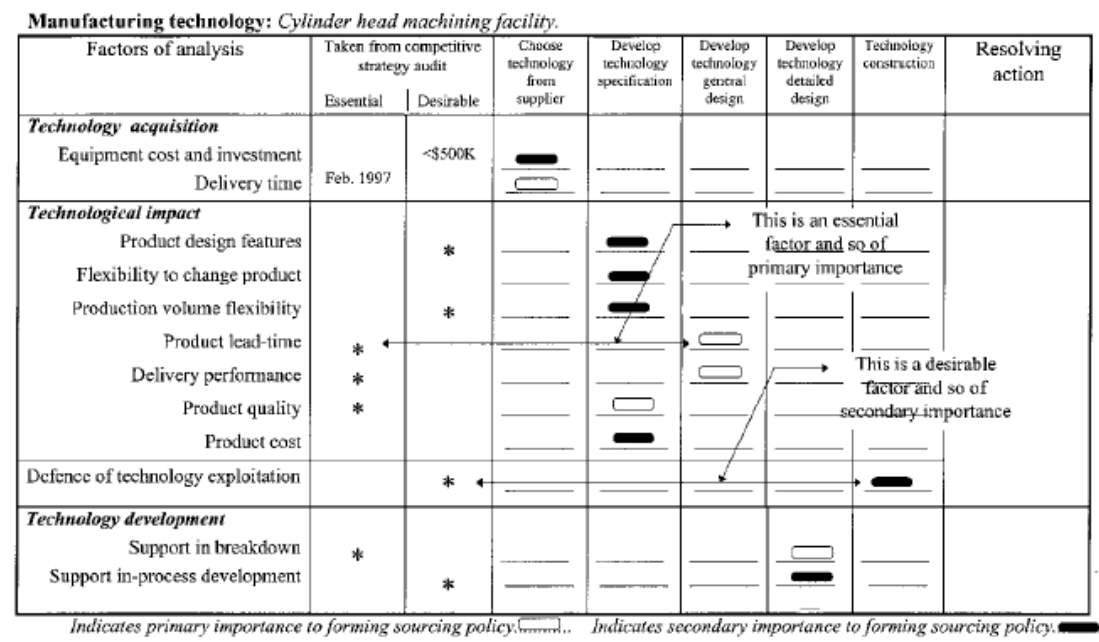

Note: The worksheet has been formed by combining the competitive strategy audit and the audit of company and supplier capabilities. The example is given for an early stage in policy formation.

Figure 8. An example of a worksheet for forming sourcing decision produced by combiningprevious analyses.

A practising manager can proceed by attempting to align the primary factors to a common sourcing option. To align these options, it may require some compromises to be formed and contingencies made. For example, it may be necessary to break down a technology into a number of subsystems, and consider these individually. Figure 9 shows how a worksheet may look after alignment of all primary factors has been achieved. Once alignment has been achieved, then the secondary factors can be considered. Each secondary factor should now be aligned with the common sourcing option determined by the primary factors. Again, various contingencies may be necessary to enable this alignment.

The alignment activity is not intended to be mechanistic, rather the analysis is intended to stimulate a thorough consideration of key sourcing issues. Reaching a consensus may be di cult. Risk analysis can be applied to assist in this task. On completion of this process, all factors should share a common sourcing option. This option then becomes the sourcing decision for the technology being considered.

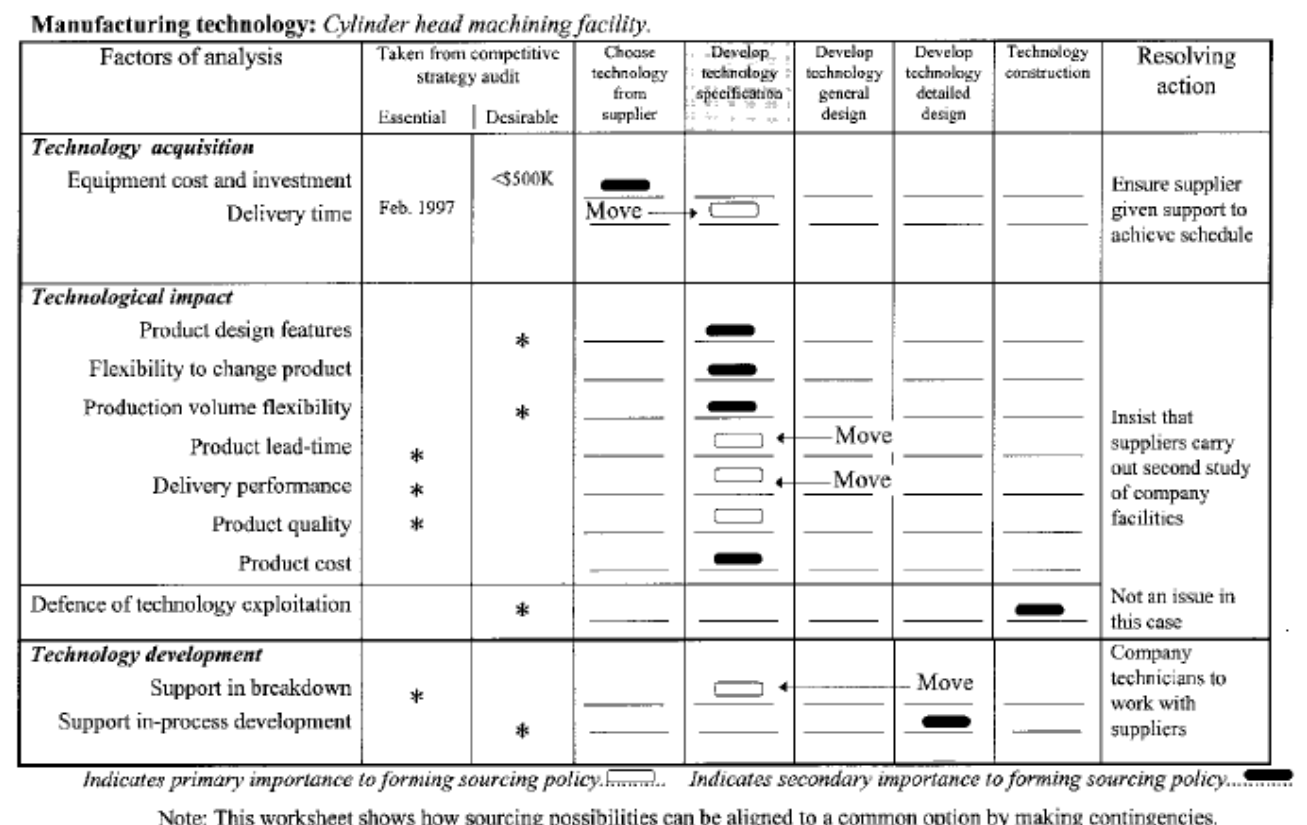

Figure 9. An example of a partially complete worksheet showing chosen technology sourcing decision.

\section{Conclusion}

This paper describes research that has explored a wide variety of US companies to understand manufacturing technology sourcing policies and how they have been formed. This structured inquiry has been carried out through a series of short case studies about technology acquisition projects at a range of manufacturing plants. Each case has 
sought to describe the technology sourcing policy, the decision process through which it has been formed, the organizational context, and the success of the policy. Cross-case analysis has then been carried out to establish the policies that occur most frequently, whether these were intended or emergent, how these policies were formed, and the motives that feature in the decision process.

On the basis of this fieldwork, this paper has described a methodology that has been established to help practising managers to form technology sourcing policies. The framework described in this paper provides a guide to ensure the consideration of key factors when a company forms a decision about vertical integration into a technology source. This methodology is now in an operational form. However, some refinement may be necessary to tailor the approach to suit specific applications. To do this, a series of further case studies is proposed to fully test the methodology in practice.

Finally, the technology sourcing decision process should be of interest to all manufacturing companies. The benefits that can be realized through a well-formed decision may vary based upon the circumstances of the company. However, as the opportunities for improvements in manufacturing performance appear ever more elusive, a competent technology sourcing policy may become a valuable asset.

\section{References}

Bruck, F., 1995, Make versus buy: The wrong decision costs. McKinsey Quarterly, 1, $28 \pm 47$.

Buchowicz, B.S., 1991, A process model of make-vs-buy decision-making; the case of manufacturing software. IEEE Transactions on Engineering Management, 38, 24ะ32.

Fine,C. H. andWhitney,D. E., 1996, Is the make \pm buy decision process a core competence? Working Paper, Sloan School of Management, MIT. Giffi, C., Roth, A. and Seal, G. M., 1990, Competing in World-class Manufacturing: America's 21st Century Challenge (Illinois: Business One Irwin).

Harrison,M. I., 1994, Diagnosing Organizations, Methods, Models and Processes (Newbury Park: Sage).

Hayes, R. H. and Wheelwright, S. C., 1984, Restoring Our Competitive Edge: Competing Through Manufacturing (New York: Wiley).

Higgins, C. C. H., 1955, Make-or-buy re-examined. Harvard Business Review, March \pm April, 33, $109 \pm 113$.

Hofer, C.W. and Schendel, D., 1978, Strategy Formulation: Analytical Concepts (St. Paul, MN: West Publishing).

Mintzberg, H., Raisinghani, D. and Theoret, A., 1976, The structure of 'unstructured' decision processes. Administrative Science Quarterly, 21, $246 \pm 275$.

Mintzberg, H., 1987, Crafting strategy. Harvard Business Review, July \pm August, $66 \pm 75$.

Pettigrew, A. M., 1988, The Management of Strategic Change (Oxford, UK: Basil Blackwell).

Porter,M. E., 1985, Competitive Advantage \pm Creating and Sustaining Superior Performance (New York: The Free Press).

Quinn, B. Q., 1995, Strategic outsourcing. McKinsey Quarterly, 1, 47 \pm 69 . Shingo, S., 1990, A Study of the Toyota Production System from an Industrial Engineering Viewpoint (Cambridge, MA: Productivity Press).

Swamidass, P.M., 1987, Planning for manufacturing technology. Long Range Planning, 20, $125 \pm 133$.

Whipp, R., Rosenfield, P. and Pettigrew, A. M., 1991, Managing the twin processes of competition and change. In Implementing Strategic Process, Change, L earning and Cooperation, editied by P. Lorange (Oxford: Blackwell Business).

Yin, R. K., 1994, Case Study Research: Design and Methods (Thousand Oaks: Sage). 